\title{
Origen y distribución de arcillas utilizadas en la fabricación de búcaros: bucarofagia en la Edad Moderna
}

\author{
Origin and distribution of the clays used for the bucaros (clay \\ vases): bucarophagy in early modern times
}

María del Pilar García Rodríguez, Facultad de Geografía e Historia, Universidad Complutense de Madrid, Espanha, mpgarcia@ucm.es

(1) https://orcid.org/0000-0002-7237-2335

Beatriz Álvarez García, Facultad de Geografía e Historia, Universidad Complutense de Madrid, Espanha, beatriz.alvarez@ucm.es

(D) htps://orcid.org/0000-0002-4985-3878

Resumen: Este artículo tiene como objetivo general estudiar el origen y la distribución de las arcillas utilizadas para fabricar los búcaros que las damas españolas de la Edad Moderna comían, después de haber bebido sus olorosas aguas. Esta costumbre, llamada "bucarofagia", estaba muy extendida entre la alta sociedad de la época, aunque su origen se remonta al siglo IX. Citada por numerosos autores de la Edad de Oro, está representada en el cuadro Las Meninas de Velázquez. Los tres yacimientos más importantes de los que se extraía la arcilla para fabricar esta cerámica se sitúan en Estremoz (Portugal), Salvatierra de los Barros (Badajoz) y Tonalá (México). En este trabajo se comparan los tres yacimientos y las características de sus arcillas. Estas arcillas están formadas por montmorillonita, con presencia de ilita, caolinita y minerales de hierro; en menor proporción aparecen cloritas, feldespatos y cuarzo. En este trabajo se realiza una revisión de los materiales originales que han formado estos yacimientos, caracterizados porque las arcillas provienen de la alteración de minerales muy ricos en hierro, preferentemente pizarras y esquistos. Se analizan sus semejanzas y diferencias con el fin de establecer la posible relación entre la composición mineralógica de las arcillas y su utilización en la fabricación de búcaros.

Palabras claves: arcilla; bucarofagia; Edad Moderna; Estremoz; Salvatierra; Tonalá.

Abstract: The aim of this paper is to analyze the origins and distribution of the clay used for the bucaros (clay vases). The bucaros were eaten by Spanish and Portuguese early modern women, after having drunk the water in it. This custom, called bucarophagy, was widely widespread among the nobility, and its origin dates back to the 9th century. During the 17th and 18th century, it appeared in essays, theatre plays and poems, and it was represented by Velazquez in its well-known picture Las Meninas. The three main sites from where the clay was extracted to make the ceramic were Estremoz (Portugal), Salvatierra de los Barros (Spain) and Tonala (Mexico). In this paper we compare the three sites and the characteristics of the clay. In the three cases the clay comes from the alteration of highly iron-rich materials, especially slate and schists. It is compounded by montmorillonite, with illite, kaolinite and iron minerals. Minor components are chlorites, feldspars and quartz. The objective is to review the parent material of the sites, highly rich in iron minerals, mainly shales and schists. From the analysis of their similarities and differences, a link is drawn between the clay's mineralogical composition and its use for the production of bucaros.

Keywords: clay; bucarophagy; early modern age; Estremoz; Salvatierra; Tonalá.

\section{Introducción}

El estudio de las arcillas es fundamental no solo para conocer la génesis y evolución de los suelos y su repercusión en las propiedades de los mismos, sino también por la 
importancia económica que estos minerales tienen en numerosas industrias cerámicas, papeleras, farmacéuticas, alimentarias, etc. El término arcilla tiene dos acepciones: texturalmente se consideran arcillas a todos aquellos minerales con tamaño inferior a dos micrómetros, pero en sentido mineralógico solo se consideran arcillas a los filosilicatos. Ambos términos convergen puesto que la mayoría de los minerales inferiores a dos micrómetros son filosilicatos. Debido a su plasticidad y que al secarse o al cocerlas adquieren consistencia, son muy empleadas en alfarería. La composición mineralógica y química de estas arcillas condiciona su uso para unos tipos u otros de cerámica.

Las arcillas han sido estudiadas desde el campo de las ciencias: químicos, farmacéuticos, edafólogos, geólogos, etc. Pero también, desde hace años, son objeto de interés para los arqueólogos que las analizan debido a la importancia que tienen para conocer las cerámicas del pasado. Desde hace unas décadas también los historiadores se han interesado por ellas para estudiar su importancia en el comercio de la alfarería entre diversos países (Bouza, 1988) y su repercusión en las costumbres de la época.

El conocimiento de las arcillas, fundamental en los estudios de suelos, es un tema arduo para la mayoría de los estudiantes del campo de la Geografía, muchos de ellos provenientes del área de ciencias sociales y a los que les cuesta entrar en el mundo del intercambio de cationes y redes de los minerales. Por ello, para hacerles más fácil su comprensión y atraer su atención es importante hacerles ver la utilidad de estos minerales microscópicos.

Entre las aplicaciones industriales de las arcillas una de las que más les sorprende a los estudiantes es su utilización en la alimentación; a partir de ahí empiezan a interesarse por la composición de estos minerales. Sin embargo, las arcillas, empleadas ahora en la fabricación de cervezas, de salchichas o de medicamentos ya fueron utilizadas como alimento desde tiempos prehistóricos. La geofagia se remonta al Neolítico, como se puede observar en el desgaste de los molares de restos humanos encontrados en distintos continentes. En el siglo XVIII, el geógrafo prusiano Humboldt relata en su Viaje a las regiones equinocciales del nuevo continente (1826) el caso de los indios de Tigua (en las cercanías de Quito, Ecuador), quienes disuelven en agua una arcilla muy fina, mezclada con arena cuarzosa, de la cual se obtiene la llamada "agua o leche de llanka", una bebida refrescante que guardaban en grandes vasijas (Achury, 1967; Guinea, 2006).

En el caso de la Península Ibérica, la costumbre de comer arcillas llega con la conquista árabe (Seseña, 1991a), quienes probablemente tomaron esta costumbre de los persas. El geógrafo Al-Idrisi señaló que las arcillas de Magán, en Toledo, eran similares a las arcillas de Nisapur, en Persia, y ambas eran comestibles (Garulo, 1987). Pero es en la Edad Moderna cuando la costumbre de comer barro se extiende entre las mujeres de las clases nobles, con predilección por comer unos recipientes arcillosos denominados búcaros. En los siglos XVI y XVII era habitual comer los búcaros utilizados para beber agua, costumbre que se mantuvo hasta el siglo XIX. En 
su Tesoro de la lengua castellana, de 1611, Sebastián de Covarrubias recogía los usos de la palabra búcaro y apuntaba sobre ella lo siguiente:

\begin{abstract}
"género de vaso, de cierta tierra colorada que traen de Portugal, y porque en la forma era ventriculoso y hinchado, le llamaron buccaro a bucca, que vale el carrillo hinchado, o puede traer origen del nombre griego ßoukapos (buqueros) que vale cuerno de buei, por aver tenido en sus principios forma de cuernos, que aún hasta oy día se usa esta hechura en todas materias. Destos barros dizen que comen las damas, por amortiguar la color, o por golosina viciosa, y es ocasión de que el barro, y la tierra de la sepultura las coma, y consuma en lo más florido de su edad" (Covarrubias, 1611, 154v).
\end{abstract}

También escritores del Siglo de Oro, como Lope de Vega (La Dorotea, El acero de Madrid), Quevedo ( $A$ Amarili, que tenía unos pedazos de búcaro en la boca), Tirso de Molina (Quien calla, otorga), Calderón (Fineza contra fineza, No hay burlas con el amor), Góngora (Dulce niña, el barro bello), e incluso Cervantes en Don Quijote, se hacen eco de la costumbre de comer búcaros. Estos se pueden observar asimismo en numerosos cuadros de pintores de la época, como Zurbarán (Bodegón con cacharros) y Murillo (Aparición de la Virgen a san Bernardo). Pero, sin duda, los casos de representación de la bucarofagia más conocidos son Las Meninas (1656) de Diego Velázquez, donde podemos observar el pequeño recipiente en manos de una menina que se lo entrega a la infanta Margarita, y el retrato de la duquesa de Béjar (ca. 1585) de Alonso Sánchez Coello, donde un enano sujeta un búcaro.

Una de las fuentes más importantes para conocer esta costumbre es el libro escrito por la condesa d'Aulnoy en 1691, titulado Relation du voyage d'Espagne (Achury, 1967). En él recoge sus vivencias de un viaje a España en el año 1679, en el que visitó Madrid y tuvo trato con condesas y marquesas de la corte. A partir de esta experiencia escribió

\footnotetext{
"que las mujeres de España demuestran, desde hace mucho tiempo, una apasionada predilección por ciertas especies de tierra arcillosa que habitualmente comen, y no en discreta cantidad, con grave riesgo de su salud. Cuando se les quiere halagar, conviene obsequiarlas con estos búcaros, que ellas llaman barro, y muchas veces su confesor les impone como penitencia el pasarse un día sin comerlos".
}

La observación extrañada de d'Aulnoy permite constatar que la bucarofagia era una práctica mucho más extendida en la Monarquía Hispánica y en Portugal que en Francia, un hecho que refleja el origen árabe de la práctica. Era también más frecuente en las mujeres (Poggi y Perujo, 1972) y estaba especialmente presente entre las clases sociales acomodadas. Junto con cerámicas "de lujo", además de porcelanas venidas de las Indias y todo un elenco de imitaciones, encontramos en los ajuares de sus casas otros objetos cerámicos, fabricados con barro rojo - y también, aunque en menor medida, con barro blanco - : los búcaros (Moratinos y Villanueva, 2013).

Así, como refería Covarrubias, bajo el nombre de búcaros (o púcaros en portugués) o el más genérico de barros (en España), tienen acomodo un variado elenco de piezas que a partir de la Edad Moderna comenzaron a proliferar en casas y palacios utilizadas 
como unos elementos decorativos más, aunque su uso principal fue el de vasos en los que tomar agua. Según los diccionarios antiguos, procede de la palabra "bucea" aludiendo al aspecto de "boca hinchada de carrillos llenos" que poseen estos contenedores de aspecto frecuentemente globular. También fueron denominados "terra sigillata" adoptando el nombre latino y evidenciando el carácter arqueologizante de este tipo de piezas que precisamente comienzan su auge en el Renacimiento (Pleguezuelo, 2000).

Es probable que la aparición y posterior evolución de estos recipientes cerámicos se encuentre en el conocido gusto ibérico por beber agua, costumbre, por otro lado, muy arraigada en el conjunto de pueblos bañados por el Mediterráneo y que en nuestra orilla sería un hábito heredado de la cultura hispanomusulmana. Los viajeros encontraban todavía más curiosa la costumbre, arraigada entre las damas de la alta sociedad, de ingerir pequeños bocados de estos vasos una vez apurado su contenido o, como se decía en la época, "el comer barros", amparándose en unos - más que dudosos - beneficios terapéuticos. Parece ser que no todas las producciones de búcaros eran objeto de ingesta, empleándose sólo ciertos tipos apenas cocidos, lo que facilitaría su disolución al contacto con el agua (Pleguezuelo, 2000), y a los que además se añadirían esencias aromáticas en sus pastas.

Así, se conocen como búcaros a aquellas vasijas de barro que, además de refrescar y perfumar el agua, podían ser comidas. No obstante, la bucarofagia prácticamente desapareció a finales del siglo XIX (Franquelo et al., 2001), aunque encontramos algunas referencias en obras actuales. Así, en la novela Cien años de soledad Gabriel García Márquez relata que una de las protagonistas, Rebeca Montiel, tenía la costumbre de comer barro.

Los búcaros han despertado la curiosidad de investigadores culturales y han sido muy estudiados desde el punto de vista etnográfico en las últimas décadas, como demuestran los estudios de Seseña (1991b) y Pleguezuelo (2000). Una recopilación de datos sobre arcillas comestibles y sus usos terapéuticos a través de la historia se puede encontrar en los trabajos de Achury (1967). Sin embargo, se ha prestado menos atención a su composición mineralógica y química y al origen de los materiales.

\section{Objetivo del estudio}

El objetivo del estudio es analizar el origen y la distribución de las arcillas utilizadas para fabricar los búcaros comestibles durante la Edad Moderna y establecer una posible relación entre la composición mineralógica de estas arcillas y su utilización en la fabricación de los búcaros. Para ello se han seleccionado los tres yacimientos más importantes de los que se extraía este material: Estremoz (Portugal), Salvatierra de Barros (España) y Tonalá (México).

\section{Metodología}

Gracias a las investigaciones de historiadores y científicos se conocen los yacimientos más importantes de arcillas a partir de los cuales se fabricaban los búcaros comestibles e, incluso, se ha analizado la composición mineralógica de algunos de 
ellos. Sin embargo, no se ha establecido un nexo entre la composición mineralógica de los materiales geológicos que dan lugar a estas arcillas y la fabricación de búcaros comestibles. En este trabajo se realiza una revisión de la información existente sobre los yacimientos de Estremoz, Salvatierra de los Barros y Tonalá y se analizan sus características, comparándolos entre sí, con el fin de ver sus semejanzas y diferencias y establecer el nexo que une a todos los yacimientos con la fabricación de búcaros.

Por tanto, las preguntas que nos planteamos en este artículo son: ¿qué caracteriza a estos búcaros, qué tipo de minerales los constituyen y qué materiales dieron origen a estos yacimientos? ¿la composición de esta cerámica comestible es similar en todos ellos? ¿es parecida también a la de aquellos yacimientos de la Península lbérica de Ios que hablaba Al Idrisi?

\section{Resultados y discusión}

\subsection{Distribución geográfica y origen de las arcillas utilizadas en los búcaros comestibles}

Aunque hay diversas opiniones respecto al origen de los búcaros comestibles en España, existe casi unanimidad en pensar que la mayoría de los barros que comían las damas hispanas en los siglos XVI y XVII procedían de México (Tonalá), Portugal (Estremoz, en la comarca del Alentejo) y de la comarca de Salvatierra de los Barros en Extremadura, si bien se han localizado cerámicas en otros lugares cuya procedencia podría ser diversa: Mérida, Badajoz, Talavera, Saelices, Salamanca...(Poggi y Perujo, 1972; Fernández et al., 1995; Franquelo et al., 2001; Seseña, 2009; Rovira y Galán, 2010; Moratinos y Villanueva, 2013).

Pero, si bien hay consenso en torno a la procedencia geográfica, no lo hay en torno a las causas de su similitud. Existe polémica sobre si lo que hace similares a cerámicas de áreas tan dispersas no es la composición original de los minerales sino el posterior proceso de engobe. ¿Puede ser el engobe lo que les confiere propiedades parecidas a todas ellas? Se denomina engobe a los primeros esmaltes, con arcilla de otro color, suspensiones de arcilla muy fina en agua que, fundamentalmente, se hacía con ilita y a veces con ceniza o sal (Franquelo et al., 2001). Por la coincidencia de los efectos que producen en la salud, similar en los búcaros extremeños, portugueses y mexicanos, se ha pensado que la causa puede ser no el tipo de arcilla con el que están hechos sino el engobe (Franquelo et al., 2001).

Los recipientes utilizados habitualmente en la época moderna para refrescar el agua corresponden a dos tipos contrastados de alfarería: barros blancos (a partir de caolín o de materiales calcáreos) y barros rojos (a partir de arcillas ricas en hierro). Estos últimos son los que se utilizaban para fabricar los búcaros. Tanto los barros colorados como las alcarrazas blancas se fabricaban básicamente para dos funciones: refrescar el agua de beber y producir aromas agradables en el ámbito doméstico. No se sabe muy bien qué olores exhalaban estas cerámicas, aunque parece que ambos tipos, blancos y rojos, producían el olor a tierra mojada. Junto a ello, hay muchos testimonios escritos que hacen pensar en otros aromas más sofisticados y atrayentes, 
especialmente en el caso de los barros colorados (Pleguezuelo, 2000), y que fueron estos olores más delicados los que dieron origen a la bucarofagia. Por tanto, son barros ricos en hierro y de tono rojizo los que se han utilizado para los búcaros, hecho confirmado por la definición que de ellos recoge el Diccionario de la Real Academia Española: "la palabra búcaro procede del mozárabe búcaro, y este del latín pocǔlum (taza, vaso). Se define como tierra roja arcillosa, que se traía primitivamente de Portugal, y se usaba para hacer vasijas que se estimaban por su olor característico, especialmente como jarras para servir agua" (D.R.A.E., 2017).

Esto no quiere decir que todas las arcillas comestibles correspondan a este tipo de filosilicatos ferruginosos, ya que, si se analizan las arcillas de las que hablaba Al-Idrisi, estas eran diferentes. Las arcillas de Magán (Toledo) se localizan en sedimentos miocenos formados por lutitas verdes, una composición similar a la de las arcillas comestibles de Nisapur, en Persia (Garulo, 1987), compuestas por esmectitas con presencia de sepiolitas, ilita, cuarzo y feldespatos. En las proximidades de Magán está también la formación de arcillas rojas de la Sagra con dominio de lutitas iliticas ricas en esmectitas e ilita y presencia de caolinita. Estas arcillas rojas de la Sagra presentan unos valores más elevados de óxidos de hierro que las arcillas de áreas próximas $(6,6 \%)$ y un contenido elevado en sílice. Tienen goethita e ilmenita, pero carecen de carbonatos (Lopez-Arce, 2011). Las arcillas de Talavera, de edad oligoceno-mioceno, son ricas en esmectitas, ilitas y caolinitas y provienen de abanicos aluviales originados a partir de materiales ígneos y metamórficos del Paleozoico. Todas estas arcillas rojas han sido también utilizadas en la industria cerámica y, posiblemente, en la fabricación de búcaros.

Para conocer el tipo de arcillas y su distribución hay que considerar la geología del área donde se localizan los yacimientos, ya que las arcillas utilizadas como materia prima para la fabricación de productos cerámicos aparecen en una gran variabilidad de ambientes genéticos (marinos, continentales, lacustres, aluviales, de alteración, etc.) y en un amplio rango de edades geológicas (desde el Precámbrico al Cuaternario), con extensa distribución geográfica (Parras, 1996). También es importante considerar los suelos a los que dan lugar para ver si son similares, puesto que a partir de su cartografía se pueden detectar algunos yacimientos arcillosos.

Es importante conocer el material del que proceden las arcillas, pues no todas ellas son adecuadas para los distintos tipos de cerámicas. Así, para realizar los búcaros se emplean arcillas rojas muy ricas en hierro procedentes en su mayoría de la alteración de rocas metamórficas, principalmente esquistos y pizarras. Según Sempere (1999), las más apropiadas son las arcillas producto de la alteración de los esquistos arcillosos y silíceos, que están presentes en yacimientos terciarios abundantes por toda la geografía peninsular. Por su gran proporción de óxido de hierro y escasez de calcio, una vez cocidas dan tonalidades encarnadas fuertes, por lo que se les denomina arcillas ferruginosas. En muchos casos también suelen presentar elevados contenidos de sílice, lo que las convierte en refractarias y por tanto utilizables para usos culinarios. Las regiones más características son aquellas en las que abundan las pizarras: Extremadura y Alentejo, así como León y Cantabria. 
Aunque se fabricaron con materiales de distinta procedencia, los más habituales y deseados eran los originarios de Portugal, Extremadura y las Indias. Por esta razón para el presente estudio se han seleccionado tres yacimientos: uno en Portugal (Estremoz), otro en Extremadura (Salvatierra) y el tercero en México (Tonalá) para comparar el origen y composición de los minerales arcillosos. También son habituales los búcaros procedentes de yacimientos de Lisboa, Cádiz, Valladolid, Cáceres, Salamanca (alrededores de Ciudad Rodrigo) y, en América, Chile y Honduras. Los búcaros ya se fabricaban en España antes del descubrimiento del Nuevo Mundo, pero la importación de barros de México reactivó su uso (Franquelo et al., 2001).

\subsection{Arcillas de Estremoz (Portugal)}

La alfarería ha seguido caminos paralelos en España y Portugal desde la época romana y aún antes, aunque la unión de las coronas de Castilla y Portugal entre 1580 y 1668 refuerza las relaciones entre ambos países, con la construcción del eje de comunicaciones Lisboa - Madrid (Bouza, 1988). En los siglos XVI y XVII algunos centros alentejanos, entre ellos Estremoz, se convierten en abastecedores de lozas y cerámicas para las ciudades españolas, lo que da lugar a procesos de transferencia de objetos, motivos artísticos y personas, asentándose una comunidad de artesanos portugueses en lugares como Salvatierra de los Barros. Además, ambas localidades son las únicas en las que se emplea la técnica del bruñido: una vez realizado el tinte se pule la parte exterior de las vasijas con un canto rodado del río para reducir su porosidad (Calero y Carmona, 2009).

Estremoz pertenece a la provincia del alto Alentejo (Figura 1) y se localiza en una antiforma, gran estructura tectónica originada durante la orogenia Varisca, formando parte del sector Estremoz-Barrancos, uno de los sectores de Ossa Morena (Oliveira, 2013). Tiene una estructura sedimentaria compleja con secuencias desde el Precámbrico al Devónico. Esta antiforma es conocida por las explotaciones de mármol desde la época romana, correspondientes al complejo vulcano sedimentario carbonatado, con una edad entre Ordovícico medio y Devónico interior (Sarmento et al., 2000). Los mármoles aparecen interestratificados con calcoesquistos y rocas volcánicas básicas (basaltos) o ácidas, pero en sus proximidades aparecen yacimientos arcillosos. Estos materiales arcillosos provienen de la alteración de esquistos y pizarras cámbricas correspondientes a la serie negra común en toda la zona de Ossa Morena. Según Bombín-Espino et al. (1995), al alterarse, estos materiales dan lugar a ilitas $\mathrm{y}$, en menor medida, a cloritas y cuarzo, junto con minerales ferromagnesianos. 


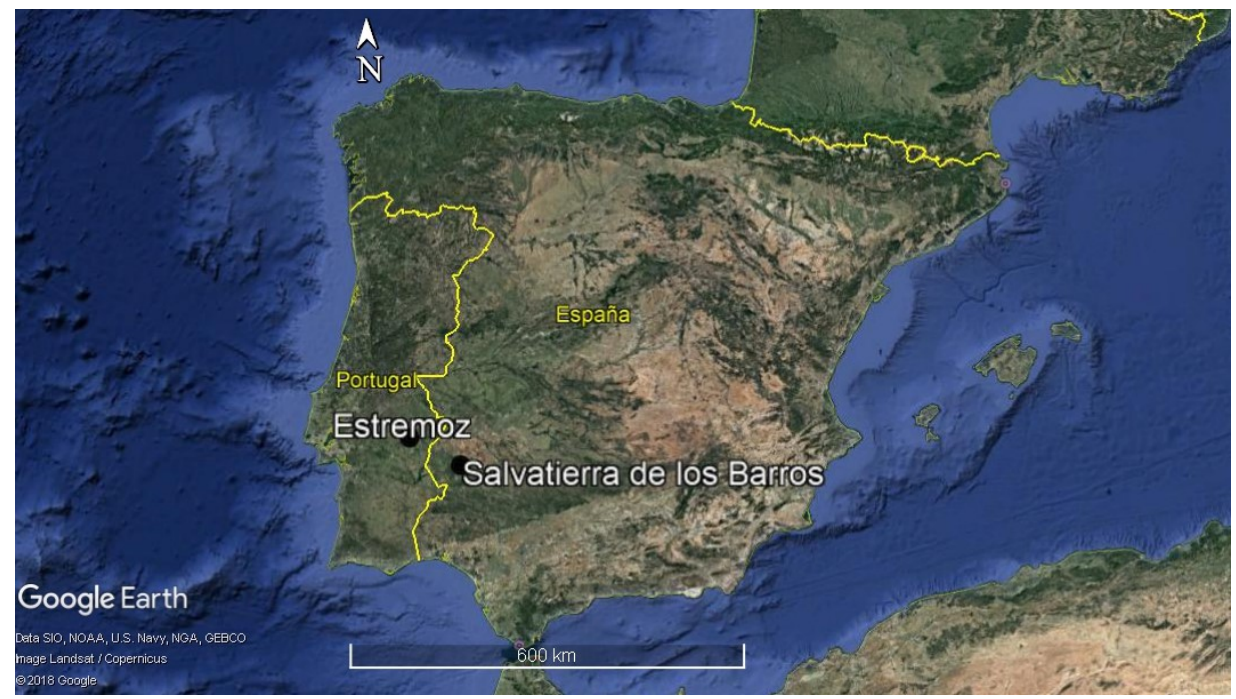

Figura 1: Localización de Estremoz y Salvatierra de los Barros en la Península Ibérica.

Fuente: Google Earth@.

Los suelos desarrollados sobre estos materiales son similares a los de Extremadura occidental, dada la misma litología de materiales paleozoicos, presencia de suelos poco evolucionados, leptosoles y regosoles con algunos cambisoles y presencia de vertisoles y luvisoles sobre los sedimentos terciarios (Berrocal, 1992).

Ruiz Gil (1999) señala que la loza de Estremoz se fabrica a partir de pasta roja con desengrasante de micas y rocas metamórficas y, en cerámica similar a ella, los arqueólogos anglosajones señalan que el desengrasante son feldespatos, lo que los portugueses llaman "empedraro" y los españoles "enchinado" (en las cerámicas entre el Duero y el Tajo) que tiene incrustaciones de cuarzo. Todo ello es lo que hace a esta cerámica comestible (Ruiz Gil, 1999).

\subsection{Arcillas de Salvatierra de los Barros (España)}

Situada en el sur de la provincia de Badajoz (Figura 1), en las estribaciones septentrionales de Sierra Morena occidental, corresponde a la red fluvial del Guadiana y se localiza sobre una penillanura con algunos relieves residuales. Pertenece a la zona de Ossa Morena, y, dentro de ella, al anticlinorio de Olivenza-Monesterio. Según la hoja de Magna 1:50.000, 853 de Burguillos del Cerro (Muelas y Soubrier, 1975), son materiales del Precámbrico superior compuestos por esquistos, grauvakas y pizarras precámbricas con intercalaciones de algunas coladas volcánicas de naturaleza básica. Aparece también una intrusión de rocas de composición granítica a granodiorítica al sur de Salvatierra y un complejo de diques de composición diabásica. En esta área son frecuentes las minas para explotación de óxidos de hierro. En consecuencia, resulta obvio admitir un fondo anormalmente rico en hierro (hematites y magnetita), como común abastecedor de las mineralizaciones existentes en la citada región, posiblemente de origen vulcano sedimentario. Al igual que sucede en Estremoz, en áreas próximas hay mármoles. 
Los suelos corresponden a leptosoles, regosoles y cambisoles, con altos contenidos en hierro. En áreas situadas más al norte, ya en la Tierra de Barros, sobre materiales terciarios y cuaternarios compuestos por arcillas, arenas, areniscas y margas que ocupan las depresiones y cuencas de sedimentación (Nuñez, 2007), se desarrollan los vertisoles característicos de la comarca, con menor presencia de leptosoles y calcisoles. Estos materiales neógenos se depositaron durante el Terciario y el Cuaternario en ambientes continentales de tipo fluvial, lacustre y fluvio-lacustre, sobre el sustrato ígneo y metamórfico de la extensa y arrasada Meseta Ibérica. Se han distinguido tres ciclos sedimentarios en los materiales terciarios y cuaternarios existentes en el área meridional. La tierra de Barros se caracteriza por la presencia de arcillas expansivas que dan lugar a los vertisoles (Gallardo y Saldaña, 1992).

Según García Ramos et al. (1974), en Salvatierra de los Barros se emplean arcillas procedentes de la meteorización de las pizarras de la "Serie Negra" de edad precámbrica. Su naturaleza mineralógica es montmorillonítico-caolinítica, con bajos contenidos en carbonatos y materia orgánica. En Salvatierra las arcillas provienen de materiales de edad cámbrica y precámbrica formados por alteración de las pizarras. Dominan montmorillonitas y caolín.

Para el bruñido que se hacía en Salvatierra y Estremoz se utilizan también materiales ricos en hierro. En Salvatierra se emplean tres tipos de barros: barro claro, barro rojo y barro rojo fuerte (Franquelo et al., 2001). Las muestras de barro claro son ricas en esmectita (montmorillonita de tipo beidillítico) con presencia de ilita y rutilo. En el barro rojo destaca la colinita con presencia de ilita y micas degradadas de tipo moscovitico y goethita (óxido de hierro hidratado). En la muestra rojo fuerte hay dominio de caolinita con mucho hematites y goethita. En menor proporción contiene también cuarzo y micas. La presencia de caolinita y el importante contenido en hierro la confirman también los análisis de materia primas de Salvatierra realizados por Franquelo et al. (2001).

\subsection{Arcillas de Tonalá (México)}

El uso de búcaros americanos no resulta sorprendente, considerando las estrechas relaciones comerciales habidas en estos siglos. Existe noticia documental, registrada en el Archivo General de Indias en Sevilla, de la llegada de cerámicas americanas a lo largo de los siglos XVI y XVII a Castilla que influyeron en algunas producciones de Talavera y Puente del Arzobispo (López Rosendo, 2013).

El municipio de Tonalá se encuentra en la actualidad en el estado de Jalisco (Figura 2). La expansión urbana reciente ha hecho que quede comprendido dentro del área metropolitana de Guadalajara, en concreto ocupando la región este de la ciudad. En el siglo XVII todo este territorio formaba parte del virreinato de Nueva España. 


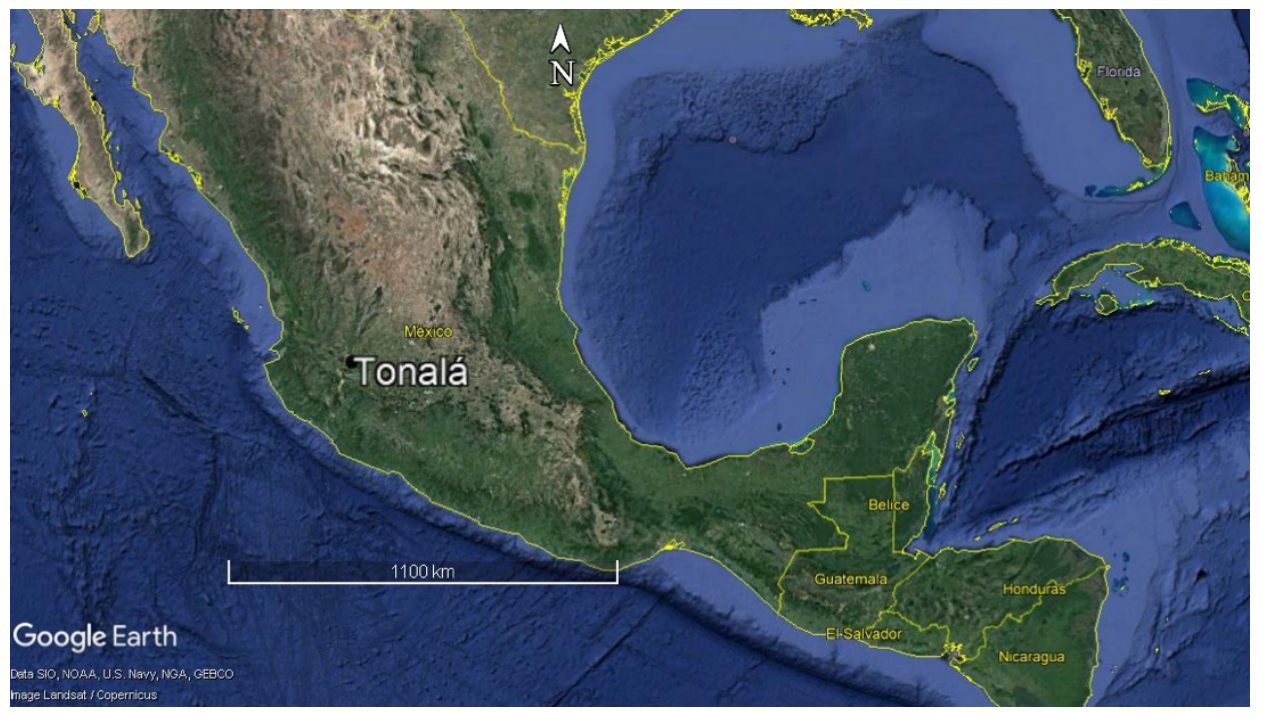

Figura 2: Localización de Tonalá en México.

Fuente: Google Earth@.

La columna estratigráfica en la región de la carta Tonalá está conformada por rocas metamórficas y plutónicas paleozoicas, cubiertas por rocas sedimentarias y volcánicas del Jurásico y Cretácico, con depósitos sedimentarios desde el Paleoceno al Cuaternario-Holoceno. Las rocas más antiguas consisten de gneises (orto y paragneises), que conforman parte del Macizo de Chiapas, de probable edad Precámbrica. Estas rocas fueron intrusionadas por metagranitos-metagranodioritas de edades permo-triásicas. Sobre las rocas que constituyen el Macizo Chiapaneco, se depositó en discordancia una secuencia metavolcanosedimentaria de edad JurásicoTithoniano-Cretácico-Neocomiano. Más recientemente se formaron depósitos del Cuaternario-Holoceno, constituidos por conglomerados poco consolidados que conforman posibles abanicos aluviales. La superficie del territorio municipal está constituida por terrenos del período cuaternario (Hernández, 2012). La composición de los suelos es de tipos predominantes regosol eútrico, faeozem háplico y luvisol crómico (Stransky, 2011).

Sobre las arcillas que se utilizaron para la fabricación de estos búcaros mexicanos se sabe que proceden, en su mayoría, del poblado de El Rosario, donde se halla el origen del barro canelo o barro de olor (Pazarín, 2013), también llamado barro mojado:

\footnotetext{
"La arcilla, materia básica utilizada por los alfareros tonaltecas, la han conseguido durante siglos en las inmediaciones de la cabecera municipal. Su obtención no representó mucha dificultad, pues el barro necesario para la construcción de la loza era localizado en distintos puntos alrededor de la antigua villa y en poblaciones aledañas como El Rosario, una de las antiguas poblaciones de Tonalá que contaba con los mejores bancos de barro lugar de origen de la cerámica más tradicional y popular. En la actualidad este yacimiento puede desaparecer porque se está urbanizando encima".
}

En el siglo XVI se utilizaban también materiales procedentes de las minas del pueblo de San Andrés (Anasaguesti y Llamas, 1941). 
El origen del material para fabricar los búcaros es volcánico en gran parte, arcillas rojas ferralíticas próximas al Cerro de la Reina, un barro canelo que está a punto de desaparecer por las consecuencias de la urbanización que señalaba Pazarín (2013). Sin embargo, muchas de las arcillas que se explotan en Tonalá provienen de materiales graníticos y son ricas en minerales del grupo del caolín, pero éstas no son útiles en alfarería salvo como revestimiento para pasta de loza, ya que aumenta la refractariedad. Sí se utilizan aquellas que tienen más contenido en clorita y en magnetita, con tono marrón rojizo, más ricas en hierro (Hernández González, 2012). Franquelo et al. (2001) analizaron una muestra procedente de Tonalá en la que encontraron montmorillonita, feldespatos (anortita), hematites y cuarzo.

El historiador Matías de la Mota Padilla escribió en 1742:

\begin{abstract}
"Tonalá tiene minas de una arcilla tan especial que no hay en todo el mundo otra similar. Y por esta razón hay tanto aprecio por estos vasos, urnas, cántaros y varias clases de figuras animales, grandes y pequeñas, tan bruñidas y perfectas que en muchas partes de Europa las mujeres comen su barro; por esta razón son vendidos por arrobas [...] en Jalapa, Veracruz y Acapulco incluso cuando está rota. Es más estimada que el cristal, que la china [porcelana], y más que los vasos de Alcora" (Seseña, 2009).
\end{abstract}

Veracruz y Acapulco eran puerto de salida de la flota de Indias (que unía el virreinato de Nueva España con Sevilla) y de la nao de Manila (que cruzaba el Pacífico), convirtiendo los productos exportados en una mercancía global. En Jalapa se celebraba desde el siglo XVIII una de las ferias más importantes del virreinato. Los barros de Tonalá fueron los más valorados porque, por sus características, eran muy aptos para contener y exhalar perfumes, tal y como demuestra Magalotti (García, 2015).

Muchos de los búcaros utilizados en España en el siglo XVII proceden de México (Seseña, 1991b). En el museo de América de Madrid se exponen numerosos búcaros pertenecientes a la colección de la condesa de Oñate, doña Luisa Manrique de Lara y Gonzaga, que, en 1885, doña Josefa de la Cerda y Palafox, condesa viuda de Oñate, decidió donar al Museo Arqueológico Nacional, de donde pasó al Museo de América de Madrid en 1941. Estos búcaros tienen su origen en Tonalá y son similares al búcaro pintado por Velázquez en Las Meninas. Estas arcillas ya habían llamado la atención de distintos historiadores en el siglo XVIII, quienes describían su fabricación como "tierra roja de América" (Mota, 1742). El olor en contacto con el agua se debe a una pasta de arcilla para el engobe que se utiliza antes de cocerla y que es rica en óxidos de aluminio. Según Ruiz Gil (1999), la serie del museo de América parece, por su técnica, corresponder a una imitación mexicana de las cerámicas de Estremoz, lo que implicaría una transferencia circular del conocimiento y los productos. La característica principal radica en el tratamiento bruñido, alisado o pintado en rojo de sus superficies lo que la convierte en una cerámica roja fina y con engobe que ha sido estudiada por numerosos autores especialmente en América (Rovira y Gaitán, 2010). Por sus características, con frecuencia se confunde con la "terra sigilata" (Fernandez Nanclares et al. 1995). 


\section{Conclusiones}

La alta demanda de búcaros por parte de las capas más pudientes de la sociedad de la Edad Moderna dio lugar a un importante comercio de vasos de arcilla que conectaba diferentes áreas geográficas del Imperio hispánico, desde los territorios americanos hasta áreas de la península ibérica. Como consecuencia de este comercio se desarrolló el trabajo de la arcilla en determinadas zonas geográficas, produciéndose una especialización y una circulación del conocimiento asociado al trabajo específico y fabricación de los búcaros. Esta circunstancia dio lugar a una serie de tradiciones culturales compartidas a ambos lados del Atlántico, que tienen su origen en una práctica hispánica, pero cuya necesidad de material provocó la convergencia con otras tradiciones en los territorios americanos.

A través de la comparativa de los tres yacimientos se puede observar cómo la búsqueda de una arcilla de características similares en color, textura y propiedades fue lo que determinó la elección de yacimientos concretos. Los tres yacimientos analizados tienen materiales precámbricos y cámbricos con presencia de extrusiones volcánicas posteriores. Las arcillas empleadas son ricas en montmorillonitas, por lo que tienen una alta proporción de arcillas expandibles, con presencia de ilita, caolinita y minerales de hierro. Son los cuatro componentes esenciales de todas ellas, aunque en menor medida aparecen otros silicatos como cloritas, feldespatos (anortitas) y cuarzos. Todas las arcillas utilizadas en la fabricación de los búcaros son pobres en carbonatos.

Las arcillas procedentes de la alteración de pizarras y esquistos precámbricos y cámbricos han sido las más utilizadas para la fabricación de búcaros ya que poseen alto contenido en hierro lo que les da la tonalidad rojiza. Sus yacimientos se localizan directamente sobre los materiales precámbricos y paleozoicos que han sufrido importantes procesos de alteración $y$, también, sobre materiales terciarios depositados durante el cenozoico en las cuencas sedimentarias. En áreas próximas hay procesos vulcano sedimentarios con formaciones ricas en hierro (hematites y goethita). Este es el origen de los búcaros de Estremoz y Salvatierra de los Barros.

Las arcillas de Tonalá tienen un origen diferente ya que provienen en su mayoría de depósitos volcánicos, aunque se asemejan a las de los otros yacimientos en su composición mineralógica y su alto contenido en hierro. Además, en áreas próximas aparecen también materiales paleozoicos que, una vez alterados, podrían dar lugar a arcillas dedicadas a este tipo de alfarería. La proporción de caolinita es menor a la de otros tipos de alfarería si bien puede ser utilizada en el engobe. En este engobe se utilizan también micas y sus productos de alteración, como ilitas.

Otras áreas con materiales precámbricos y paleozoicos similares, con presencia de pizarras muy ricas en hierro y fuertemente alteradas pueden servir para fabricar el mismo tipo de alfarería.

Los datos que se tienen sobre arcillas comestibles en épocas anteriores a la Edad Moderna indican que tenían una composición diferente a las utilizadas para la fabricación de los búcaros, ya que muchas de ellas procedían de materiales terciarios 
ricos en esmectitas, sepiolita, ilita, cuarzo y feldespatos, aunque en su origen estas arcillas provienen también de la alteración de rocas ígneas y metamórficas del Paleozoico.

Los suelos de Estremoz y Salvatierra de los Barros, son muy similares: leptosoles, cambisoles y regosoles, con presencia de vertisoles y, en menor medida, luvisoles y calcisoles. Leptosoles y cambisoles aparecen sobre los materiales originales (pizarras y esquistos) sin apenas alteración, mientras que las demás unidades se forman sobre los materiales alterados con alto contenido en arcilla. Los vertisoles son ricos en montmorillonitas. En Tonalá se han cartografiado regosoles, faeozem y luvisoles, estos últimos con alto contenido en arcillas.

Aunque la bucarofagia casi desapareció a finales del siglo XIX, debido al desarrollo de los conocimientos médicos, que cada vez más señalaban los potenciales riesgos para la salud de esta práctica, y a los cambios en los hábitos culturales, tanto los búcaros como estos yacimientos son los reflejos de una práctica cultural centenaria. Debido a su importancia, tanto histórica como geológica, sería aconsejable preservar estos yacimientos y convertirlos en centros de difusión del patrimonio cultural, con el fin de conservar la memoria de la práctica de la bucarofagia.

\section{Referencias}

Achury Valenzuela, D. (1967). Comer tierra. Boletín cultural y bibliográfico, 10 (7), 1529-1540.

Anasaguesti y Llamas, J. (1941). Tonalá: ayer y hoy, 1892. Edit. Navarrete.

Berrocal Rangel, L. (1992). El marco geográfico. Complutum, vol extra 2 (Los pueblos célticos del suroeste de la Península Ibérica), 73-92.

Bombin-Espino, M., Piçarra, J. M., Oliveira, J. T., Saavedra, J. y Gutierrez-Marco, J. C. (1995). Estudio geoquímico preliminar de las liditas y pizarras negras siluricas de la region de moura-barrancos (zona de ossa-morena,sur de Portugal). XIII RGOP/PICG (pp. 319-320), Septiembre 1995.

Bouza, F. (edit.) (1988). Cartas de Felipe I/ a sus hijas. Turner, Madrid, 78-79.

Calero, J. A. y Carmona, J. D. (2009). La historia y la alfarería de Salvatierra de los Barros contada desde su museo de identidad. Revista de Estudios Extremeños, LXV (I), 75-100.

Calero, J. A. y Carmona, J. D. (2012). La alfarería tradicional para agua de Salvatierra de los Barros en la representación popular. Historia y problemática actual y otros estudios sobre Extremadura. XIII Jornadas de Historia en Llerena (pp. 425-449). Llerena, Sociedad Extremeña de Historia.

Covarrubias, Sebastián de (1611). Tesoro de la Lengua castellana o española. Madrid, impreso por Luis Sánchez.

De la Mota Padilla, M. (1973). Historia del Reino de Nueva Galicia en la América Septentrional (1742). Universidad Guadalajara.

D.R.A.E. (2017). Diccionario de la Real Academia Española de la Lengua. Madrid. 
Fernández Nanclares, A., Miguel Martín Montes, Á. y Moreda Blanco, J. (1995). Arqueología de San Benito (Valladolid). La cerámica bucarina de tipo "orfebre": origen tipología y dispersión. Fundación Municipal de Cultura. Excmo. Ayuntamiento de Valladolid.

Franquelo, M. L., Pérez- Rodríguez, J. L. y Seseña, N. (2001). Caracterización de materias primas y muestras cocidas de utilidad como búcaros. In Gómez, B., Respaldiza, M. A. y Pardo M. L. (Eds.) III Congreso nacional de Arqueometría, (pp. 315-324). Ed. Univ. de Sevilla,

Gallardo, J. y Saldaña, A. (1992). Génesis, clasificación y problemas agronómicos de los barros: Tierra de Barros, Extremadura. Anales de Geografía de la Universidad Complutense, 12, 265-275.

García, L. (2015). Remedio terapéutico o vicio. La ingesta de barro en el siglo de Oro. Pasea por Madrid, 5, 48-59.

García Ramos, G., Rodríguez Montero, R. y Mesa, J. M. A (1974). Materias primas y. técnicas empleadas en artesanía popular de la tierra cocida de Extremadura. Estudios Geológicos, XXX, 407-421.

Garulo, T. (1987). Comer barro (Nota al capítulo XXX del Kitab al-muwassa de al-Wasssa). Al-qantara. Revista de estudios árabes, 8, 1-2, 153-164.

Guinea, M. (2006). El uso de tierras comestibles por los pueblos costeros del Periodo de Integración en los Andes Septentrionales. Bulletin de l'Institut Français d'Études Andines, $35,3,321-334$.

Hernández González, J. A. (2012). Inventario físico de los recursos minerales de la carta Tonalá. E 15-C87. Escala 1:50.000. Municipios Tonalá, Arriaga y Miraflores, estado de Chiapas. Servicio Geológico Mexicano, 76 p.

López Rosendo, E. (2013). Cerámica indígena mexicana de los primeros contactos coloniales en el Puerto de Santa María (Cádiz, España). Revista de Historia de El Puerto, 50, 35-78.

López Rosendo, E. y Ruiz Gil, J. A. (2012). El alfar de época moderna del jardín de Cano (EI Puerto de Santa María) y las producciones cerámicas de la bahía de Cádiz entre los siglos XVII y XVIII. Revista de Historia de El Puerto, 48, 9-67.

López-Arce Martínez, P. (2011). Ladrillos de edificios históricos de Toledo. Caracterización, origen de las materias primas y aplicaciones para su conservación y restauración. Tesis doctoral, Universidad Complutense de Madrid, España.

Magalotti, L. (1972). De los búcaros de las Indias occidentales. Boletín del Instituto de Investigaciones Bibliográficas UAM. Consultado em http://publicaciones.iib.unam.mx/index.php/boletin/article/viewFile/270/262

Moratinos García, M. y Villanueva Zubizarreta, O. (2013). Usos, modas y cambios: el gusto por los "barros de Portugal" en la cuenca del Duero y sus réplicas hispanas durante el antiguo régimen. BSAA Arqueología, LXXIX, 153-175.

Muelas, A. y Soubrier, J. (1975). Hoja MAGNA 853, Burguillos del Cerro. Escala 1:50.000. Mapa Geológico de España, IGME, Madrid.

Núñez, A. (2007). Guía integral de recursos de la comarca Sierra Grande-Tierra de Barros. Ed. FEDESIBA, Junta de Exteremadura. 
Oliveira, J. T. (2013). Geologia da Região da Antiforma de Estremoz. VII Encontro de professores de Geociências do Alentejo e Algarve. Estremoz.

Parras, J. (1996). Mineralogía y propiedades cerámicas de pizarras paleozoicas de Ciudad Real. Tesis Doctoral. Ed. Universidad de Castilla La Mancha, España.

Pazarín V.M. (2013). Resguardar la inminente pérdida. Consultado em 10/5/2019, em http://www.gaceta.udg.mx/Hemeroteca/paginas/763/G763 REG\%203.pdf

Pleguezuelo Hernández, A. (2000). Cerámicas para agua en el barroco español: una primera aproximación desde la literatura y la pintura. Ars Longa, 9-10, 123-138.

Poggi, T. y Perujo, F. (1972). De los búcaros de las Indias Occidentales de Lorenzo Magalotti. Boletín de Investigaciones Bibliográficas 11, 8, 319-354.

Rovira, B. y Gaitán, F. (2010). Los búcaros: de las Indias para el mundo. Canto Rodado, 5, 39-78.

Ruiz Gil, J. A. (1999). Arqueología en la Bahía de Cádiz durante la Edad Moderna. Tesis Doctoral, Universidad de Huelva, España.

Ruiz P. (dirección) (2009). MAGNA, Hoja 627, Talavera de la Reina. Escala 1:50.000. Mapa Geológico de España, IGME, Madrid.

Sarmento, G. N., Piçarra., J., Oliveira, J. T. (2000). Conodontes do Silúrico (¿Superior?) Devónico nos "Mármores de Estremoz", sector de Estremoz-Barrancos, Zona de OssaMorena, Portugal. Implicações estratigráficas e estruturais a nível regional. I Congresso Ibérico de Paleontologia/VII Internacional Meeting do Projecto IGCP 421 (pp. 284-285), Évora.

Sempere, E. (1999). Catalogación de arcillas - técnicas y acabados de la alfarería Hispano Portuguesa. Boletín de la Sociedad Española de Cerámica y Vidrio, 38, 369-376.

Seseña, N. (1991). El búcaro de las Meninas. Velazquez y el arte de su tiempo. $V$ Jornadas de arte. C.S.I.C. Madrid.

Seseña, N. (1991). Los barros y lozas que pintó Velazquez. C.S.I.C. Archivo Español de Arte, 64, 254. Madrid, Centro de Estudios Históricos, C.S.I.C. pp. 171-180.

Seseña, N. (2009). El vicio del barro. Ed. El Viso. Madrid.

Stransky, F. A. (2011). Atlas de riesgos naturales del municipio de Arriaga, Chiapas. Reporte Final. Ayuntamiento de Arriaga.

Artigo recebido em / Received on: 15/07/2019

Artigo aceite para publicação em / Accepted for publication on: 22/10/2019 
García Rodriguez y Álvarez Garcia / Physis Terrae, Vol. 1, n 1, 2019, 57-71

Página intencionalmente deixada em branco 